\title{
Mapping snow depth in alpine terrain with unmanned aerial systems (UASs): potential and limitations
}

\author{
Yves Bühler $^{1}$, Marc S. Adams ${ }^{2}$, Ruedi Bösch ${ }^{3}$, and Andreas Stoffel ${ }^{1}$ \\ ${ }^{1}$ WSL Institute for Snow and Avalanche Research SLF, Davos, Switzerland \\ ${ }^{2}$ Austrian Research Centre for Forests (BFW), Innsbruck, Austria \\ ${ }^{3}$ Swiss Federal Institute for Forest, Snow and Landscape Research WSL, Birmensdorf, Switzerland \\ Correspondence to: Yves Bühler (buehler@slf.ch)
}

Received: 30 November 2015 - Published in The Cryosphere Discuss.: 14 January 2016

Revised: 15 April 2016 - Accepted: 25 April 2016 - Published: 23 May 2016

\begin{abstract}
Detailed information on the spatiotemporal snow depth distribution is a crucial input for numerous applications in hydrology, climatology, ecology and avalanche research. Today, snow depth distribution is usually estimated by combining point measurements from weather stations or observers in the field with spatial interpolation algorithms. However, even a dense measurement network like the one in Switzerland, with more than one measurement station per $10 \mathrm{~km}^{2}$ on average, is not able to capture the large spatial variability of snow depth present in alpine terrain.

Remote sensing methods, such as laser scanning or digital photogrammetry, have recently been successfully applied to map snow depth variability at local and regional scales. However, in most countries such data acquisition is costly if manned airplanes are involved. The effectiveness of ground-based measurements on the other hand is often hindered by occlusions, due to the complex terrain or acute viewing angles. In this paper, we investigate the application of unmanned aerial systems (UASs), in combination with structure-from-motion photogrammetry, to map snow depth distribution. Compared to manual measurements, such systems are relatively cost-effective and can be applied very flexibly to cover terrain not accessible from the ground. In this study, we map snow depth at two different locations: (a) a sheltered location at the bottom of the Flüela valley (1900 ma.s.1.) and (b) an exposed location on a peak (2500 $\mathrm{m}$ a.s.1.) in the ski resort Jakobshorn, both in the vicinity of Davos, Switzerland. At the first test site, we monitor the ablation on three different dates. We validate the photogrammetric snow depth maps using simultaneously acquired manual snow depth measurements. The resulting snow depth val-
\end{abstract}

ues have a root mean square error (RMSE) of less than 0.07 to $0.15 \mathrm{~m}$ on meadows and rocks and a RMSE of less than $0.30 \mathrm{~m}$ on sections covered by bushes or tall grass, compared to manual probe measurements. This new measurement technology opens the door for efficient, flexible, repeatable and cost-effective snow depth monitoring over areas of several hectares for various applications, if the national and regional regulations permit the application of UASs.

\section{Introduction}

Information on the spatiotemporal distribution of snow depth (HS) is important for numerous applications, as it is a robust indicator for the amount of water stored as snow (snow water equivalent - SWE) (Jonas et al., 2009). It has a substantial impact on water supply and hydropower. The quality of hazard forecasting for floods and snow avalanches depends substantially on snow depth information (Bavay et al., 2009; McClung and Schaerer, 2006). The growth and habitat patterns of alpine flora and fauna are linked to the seasonal snow depth distribution (Bilodeau et al., 2013; Mysterud et al., 2001; Wipf et al., 2009). Annual changes in snow depth over the winter season have a strong impact on alpine tourism as more and more ski resorts depend on technical snow production.

Numerous studies report a very high spatial variability of snow depth within small distances, in particular in alpine terrain (Egli et al., 2011; Elder et al., 1998; Grünewald et al., 2010; Schweizer et al., 2008). Remote sensing is useful to monitor this spatial variability, because it can provide spa- 
tially continuous measurements at a high resolution of otherwise inaccessible areas. We define snow depth according to Fierz et al. (2009) as the vertical distance from the base to the snowpack surface at a specific location.

Terrestrial laser scanning (TLS) has been successfully applied in many case studies to measure HS distribution in small catchments with high vertical accuracies in the range of $0.10 \mathrm{~m}$ (Deems et al., 2013; Grünewald et al., 2010; Melvold and Skaugen, 2013; Mott et al., 2010; Prokop, 2008; Schaffhauser et al., 2008). A recent study by Deems et al. (2015) uses TLS to visualize the HS distribution in avalanche release zones for the education of ski resort staff and assesses the different error sources. However, TLS accuracies suffer from acute illumination angles, resulting in unfavorable laser footprints, in particular within flat areas. Furthermore, terrain sections behind convex landforms such as hills or moraines cannot be covered. Airborne laser scanning (ALS), on the other hand, is still very costly (e.g., Bühler et al., 2015a). Therefore, airborne digital photogrammetry is a promising and economic option for HS mapping in alpine terrain, in particular if it can be performed with cost-effective UASs.

First attempts to photogrammetrically map snow depth with analog imagery collected from manned aircrafts were already made decades ago (Cline, 1993, 1994; Smith et al., 1967). However the reported efficiency and the achieved accuracies of more than $1 \mathrm{~m}$ were insufficient for most applications. With the advent of digital photogrammetry, this changed fundamentally. Recent investigations report accuracies in the range of centimeters to decimeters, which allow a detailed analysis of the spatial variability of the mountain snow cover (Bühler et al., 2015a; Lee et al., 2008; Nolan et al., 2015) but still require a fully equipped manned aircraft and the corresponding maintenance logistics.

Recently, UASs were applied to a wide range of mapping and monitoring studies in mountainous regions, especially with a focus on natural hazards. Fernández et al. (2015) provide an extensive overview of current surveys of landslides; Ryan et al. (2015) and Whitehead et al. (2013) published UAS applications on glaciers; Danzi et al. (2013) reported on rockfall, Dall'Asta et al. (2015) on rock glaciers and Tampubolon and Reinhardt (2015) on volcano mapping. Enßle et al. (2015) successfully tested UAS data acquisition in elevations up to $4200 \mathrm{~m}$ a.s.l., proving that UASs are capable of operating at very high altitudes. However, to this date, the number of studies dealing with UAS-based photogrammetry to map snow and avalanches is very limited. First, results have recently been published by de Michele et al. (2016), Eckerstorfer et al. (2016) and Vander Jagt et al. (2015). Additionally, Basnet et al. (2015), Prokop et al. (2015) and Thibert et al. (2015) reported on using ground-based photogrammetry for snow and avalanche detection. de Michele et al. (2016) conclude that UAS-based HS mapping holds great potential, but that further studies are required especially with regard to multi-temporal mapping, sensors capable of measuring in near-infrared wavelengths or the mapping of different snow cover conditions (new snow, wet snow, ice crusts etc.).

\section{Methods: UASs and data processing}

\subsection{UAS AscTec Falcon 8}

The UAS missions have been performed with an Ascending Technologies (AscTec) Falcon 8 octocopter equipped with a customized Sony NEX-7 camera. The Falcon 8 has been in serial production since 2009 and can be customized with different sensor systems. The system weighs $2.3 \mathrm{~kg}$ (incl. camera) and can be transported to remote locations fully assembled in a special backpack, a prerequisite for most alpine applications. A combination of on-board navigation sensors (Global Navigation Satellite System, GNSS, Inertial Measurement Unit, IMU, barometer and compass) and an adaptive control unit permit high positional accuracy of better than $2.5 \mathrm{~m}$ (Ascending Technologies, personal communication, 2015) and stable flight characteristics, even in challenging, alpine environmental conditions. The specifications of the Falcon 8 are listed in Table 1.

The Sony NEX-7 system camera features a 24 MP APS$\mathrm{C}$ CMOS sensor and is equipped with a small and lightweight Sony NEX $20 \mathrm{~mm} \mathrm{~F} / 2.8$ optical lens $(81 \mathrm{~g})$. By removing the built-in short pass filter, the camera sensor is also sensitive in the near-infrared spectrum. This allows us to mount the lens with different filters for visible (RGB) and near-infrared (NIR) bands $(\lambda>550 \mathrm{~nm}, \lambda>770 \mathrm{~nm}$ and $\lambda>830 \mathrm{~nm}$ ); without a filter the camera sensor operates in a combined visual and NIR range. The near-infrared sensitivity has advantages for snow (Bühler et al., 2015b) and vegetation (Tucker, 1979) analysis. The camera is connected to the Falcon 8 by a gimbal with active stabilization and vibration damping and is powered by the UAS battery. The viewfinder of the camera is transmitted to the ground control station as video signal and the basic camera functions such as the exposure time can be controlled from the ground.

The UAS missions are planned using the AscTec Navigator software on a tablet computer. Topographic maps are imported and the waypoint navigation is calculated based on camera specifications, desired ground sampling distance (GSD) and image overlap. At the location of a planned mission, the tablet computer is connected to the ground control station and last corrections to the flight plan, e.g., due to unexpected terrain variations, can be applied. During the flight mission, the UAS automatically moves from waypoint to waypoint; only the launch and final landing phase require manual interaction.

From our experience, portability of the UAS, a high image resolution and the ability to take off and land from an exposed site are key features for photogrammetric UAS missions within alpine, snow-covered terrain. The Falcon 8 offers a good compromise between flight endurance, payload and stability in most conditions. The radiometric and spa- 
Table 1. Technical specifications of the Falcon 8 UAS.

\begin{tabular}{|c|c|}
\hline UAS type & V-form octocopter \\
\hline Dimensions & $770 \times 820 \times 125 \mathrm{~mm}$ \\
\hline Engines & Eight electrical, brushless motors \\
\hline Rotor diameter & $8^{\prime \prime}(\sim 0.20 \mathrm{~m})$ \\
\hline Number of rotors & 8 \\
\hline Rotor weight & $6 \mathrm{~g}$ \\
\hline Empty weight & $1.1 \mathrm{~kg}$ \\
\hline Max. take off weight & $2.3 \mathrm{~kg}$ \\
\hline Max. payload weight & $0.8 \mathrm{~kg}$ \\
\hline Max. flight time per battery & $12-22 \mathrm{~min}$ \\
\hline Max. range & $1 \mathrm{~km}$ \\
\hline Tolerable wind speed & $12-15 \mathrm{~m} \mathrm{~s}^{-1}$ \\
\hline \multirow[t]{2}{*}{ Navigation sensors } & AscTec Trinity (IMU, barometer and compass) \\
\hline & AscTec High-Performance GPS (GNSS) \\
\hline \multirow[t]{4}{*}{ Max. airspeed } & Manual mode $15 \mathrm{~ms}^{-1}$ \\
\hline & Height mode $15 \mathrm{~m} \mathrm{~s}^{-1}$ \\
\hline & GPS mode $4.5-10 \mathrm{~m} \mathrm{~s}^{-1}$ \\
\hline & Data acquisition $10 \mathrm{~m} \mathrm{~s}^{-1}$ \\
\hline \multirow[t]{3}{*}{ Max. climb/sink rate: } & Manual mode $6-10 \mathrm{~m} \mathrm{~s}^{-1}$ \\
\hline & Height mode $3 \mathrm{~m} \mathrm{~s}^{-1}$ \\
\hline & GPS mode $3 \mathrm{~m} \mathrm{~s}^{-1}$ \\
\hline \multirow[t]{2}{*}{ Wireless communication } & Two independent (diversity) control/data links $2.4 \mathrm{GHz}$ link (10 to $63 \mathrm{~mW}$ ) \\
\hline & One analogue diversity video receiver $5.8 \mathrm{GHz}(25$ or $100 \mathrm{~mW})$ \\
\hline LiPo battery & PP 6250, three cells $6250 \mathrm{mAh}(\sim 426 \mathrm{~g})$ \\
\hline
\end{tabular}

tial resolution of the Sony NEX-7 camera enable the generation of highly accurate digital surface models (DSMs). The portability is excellent, as the UAS, radio modem and controlling computer fit to a daypack. The short flight time per battery charge, on the other hand, is a critical disadvantage of the octocopter technology. From our experience, longer flight times are the major advantage of fixed-wing UASs, like the eBee (sensefly). However, the available cameras have only low image resolution due to limited payload capacity, space and battery power. Larger fixed-wing drones, like the Sirius Pro from MAVinci, the UX5 from Trimble or the Q-200 from Quest UAS, suffer from quite bulky overall equipment and are therefore difficult to fly in high mountain areas. Feasible terrain (large flat areas) to safely land them does often not exist. For an extensive overview of currently available UASs, the reader is referred to Colomina and Molina (2014).

The regulations for flying UASs vary a lot from country to country or even between different states or communities. If it is necessary to get flying permits long before data acquisition, this limits the applicability and flexibility of this technology considerably. The regulations in Switzerland are quite user-friendly and are easy to fulfill. The UAS has to be within line of sight and the pilot has to be able to interrupt the flight at any time. Special permission is only necessary if crowds (more than 24 people within short distance) are present within the overflown area or the area is close to an airport (Swiss regulations: http://www.bazl.admin.ch). How- ever, before applying UASs, the local regulations have to be checked carefully.

\subsection{Data processing}

The images are processed with Agisoft PhotoScan Pro v1.1.6, to generate georeferenced DSMs and orthophotos using dense point cloud generation with the default parameters. PhotoScan is based on a structure-from-motion (SfM) algorithm (Koenderink and van Doorn, 1991; Verhoeven, 2011) and provides a complete photogrammetric workflow with special emphasis on multi-view reconstruction of UASbased images. The tie point matching in PhotoScan allows the estimation of the internal and external camera orientation parameters and is followed by adding georeference information (coordinate system and reference points). The resulting model is linearly converted using a seven-parameter Helmert transformation, and therefore only compensates linear misalignment. Nonlinear deformations from the model are removed by optimizing the estimated point cloud and camera parameters using four radial and four tangential distortion coefficients (Agisoft PhotoScan User Manual, http://www.agisoft.com/downloads/user-manuals/). During creation of the dense point cloud, the estimated camera positions are used to calculate depth information for each camera and will be combined into a single dense point cloud. Two parameters of the dense cloud processing step have the strongest impact on the resulting point cloud. 


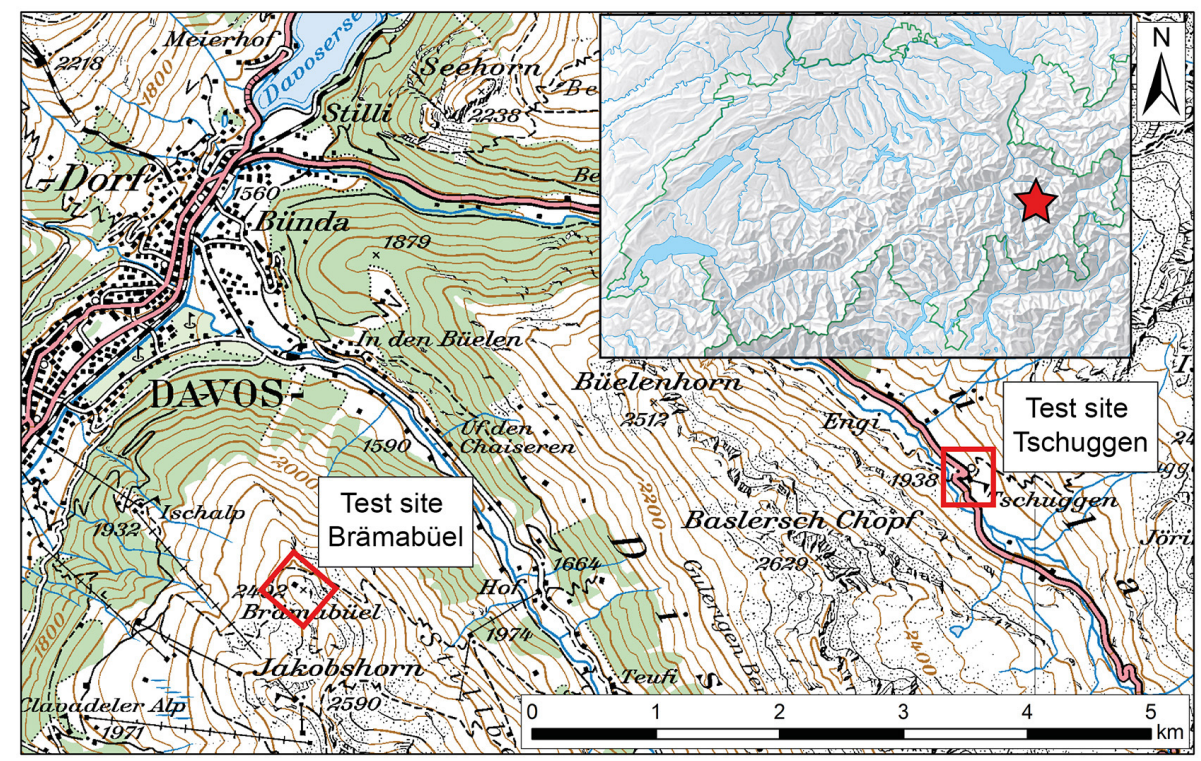

Figure 1. Location of test sites Tschuggen and Brämabüel close to Davos, Switzerland; Pixmap ${ }^{\circledR} 2015$ swisstopo (5 704000000 ), reproduced by permission of swisstopo (JA100118).

1. "Quality" defines the desired reconstruction detail level. Higher quality settings can be used to obtain more detailed and more accurate geometry, but can result in much longer processing time.

2. "Depth filtering" allows outliers from the point cloud, which are caused by poor texture of the scene, noisy or blurry images, to be removed. Depending on the complexity of the scene geometry, different depth filtering modes can be applied. The accuracy of the exported product needs to be analyzed to estimate the complexity of the model and thus select an appropriate depth filtering mode.

\section{Test sites and data acquisition}

To test the feasibility of UAS-based HS change mapping, two easily accessible test sites in the region of Davos, Switzerland, have been chosen that represent typical terrain characteristics of high alpine environments (Fig. 1).

\subsection{Tschuggen: sheltered valley bottom}

The test site Tschuggen is at the bottom of the Flüela valley at an elevation of $1940 \mathrm{~m}$ a.s.l. very close to the timberline. This spot is well accessible even during the winter season, because the Flüela pass road is regularly cleared until this point. The high alpine valley bottom features both flat alpine meadows and hilly alpine terrain. The main land cover is a mixture of bushes (mainly alpine rose, juniper and erica) containing steep rocky outcrops and sparse larch and pine trees (Fig. 10). Only moderate HS variability can be expected at this site in an average winter season because it is not usually exposed to high winds. The mean slope angle of the test site is $19^{\circ}$ ranging from 0 to $80^{\circ}$. The reference measurement plots have been acquired in areas between 4 and $36^{\circ}$ slope angle with an average slope angle of $20^{\circ}$.

A total of 252 images were acquired at this $400 \mathrm{~m} \times 300 \mathrm{~m}$ test site on four different dates between March and September 2015 (Table 2; Fig. 2). Based on our experience with different overlaps, we estimate that an image overlap of $70 \%$ along-track and across-track is a good compromise between the time required for data acquisition and quality of the resulting DSM. The first three flights were done with an old version of the AscTec flight control hardware, which required the UAS to stop and stabilize for every image acquisition, consuming considerably more time and energy to cover a specific area. The last data acquisition was performed with an updated software version where the UAS does not stop, enabling the acquisition of up to 5 times more images with one battery charge. Thus the Tschuggen test site can be covered within $5 \mathrm{~min}$ and with one battery charge. The air temperature on the flight dates, measured at an automated weather station (AWS) located $4 \mathrm{~km}$ southeast of the test site and $450 \mathrm{~m}$ higher, was between -5 and $+0.5^{\circ} \mathrm{C}$. The mean wind speeds ranged from 4 to $22 \mathrm{~km} \mathrm{~h}^{-1}$, the maximum wind speeds from 18 to $45 \mathrm{~km} \mathrm{~h}^{-1}$.

For the absolute orientation, selected reference points (RPs) were applied, which were required to be clearly visible in the base imagery on all four acquisition dates. The RPs, bright quartz marks on rocks and center lines of the road, were measured with a Leica TPS 1200 differential GNSS with an expected accuracy of better than 
Table 2. Data acquisition parameters for Tschuggen.

\begin{tabular}{lcrrrr}
\hline Acquisition date & Images & $\begin{array}{r}\text { Covered } \\
\text { area }\end{array}$ & $\begin{array}{r}\text { Mean flight } \\
\text { height above } \\
\text { ground }\end{array}$ & $\begin{array}{r}\text { Average } \\
\text { points } \\
\text { per } \mathrm{m}^{2}\end{array}$ & $\begin{array}{l}\text { Reference } \\
\text { measurements }\end{array}$ \\
\hline $\begin{array}{l}\text { 11 March 2015 } \\
\text { close to peak of winter }\end{array}$ & 43 & $57000 \mathrm{~m}^{2}$ & $97 \mathrm{~m}$ & 772 & $\begin{array}{l}12 \text { plots } \\
\text { (60 single points) }\end{array}$ \\
\hline $\begin{array}{l}24 \text { April 2015 } \\
\text { snowmelt ongoing }\end{array}$ & 55 & $87000 \mathrm{~m}^{2}$ & $126 \mathrm{~m}$ & 469 & $\begin{array}{l}19 \text { plots } \\
\text { (95 single points) }\end{array}$ \\
\hline $\begin{array}{l}\text { 12 March 2015 } \\
\text { snowmelt nearly completed }\end{array}$ & 55 & $91000 \mathrm{~m}^{2}$ & $130 \mathrm{~m}$ & 439 & $\begin{array}{l}19 \text { plots } \\
\text { (95 single points) }\end{array}$ \\
\hline $\begin{array}{l}\text { 28 September 2015 } \\
\text { completely snow-free }\end{array}$ & 99 & $128000 \mathrm{~m}^{2}$ & $113 \mathrm{~m}$ & 563 & - \\
\hline
\end{tabular}

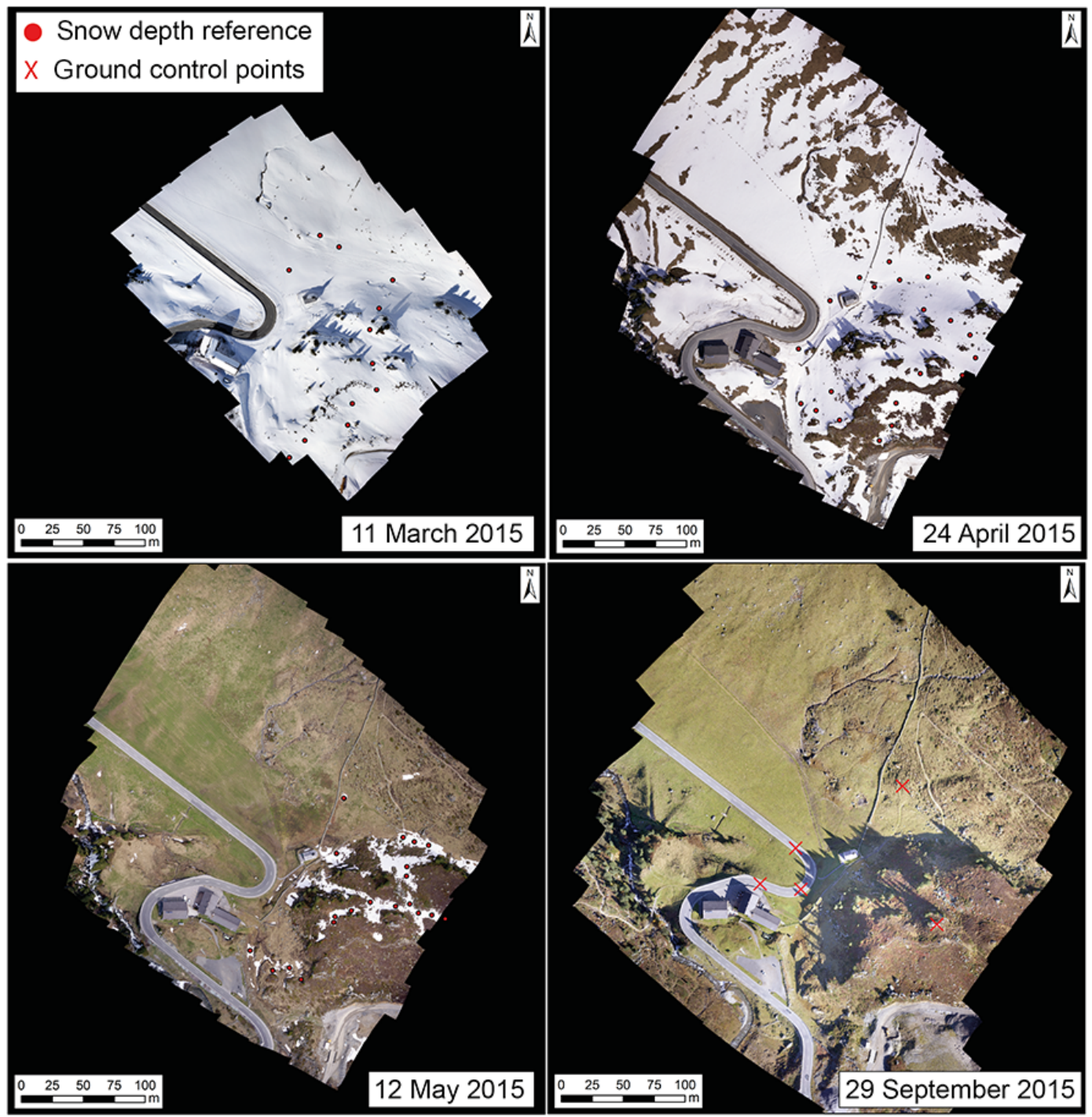

Figure 2. Orthophotos of the four different data acquisitions at Tschuggen depicting the change in snow coverage overlaid by the locations of the manual HS measurements and the applied reference points. 
Table 3. Data acquisition parameters for the Brämabühl test site.

\begin{tabular}{lrcccc}
\hline Acquisition date & $\begin{array}{r}\text { No. of } \\
\text { images }\end{array}$ & $\begin{array}{c}\text { Covered } \\
\text { area }\end{array}$ & $\begin{array}{c}\text { Mean flight } \\
\text { height above } \\
\text { ground level }\end{array}$ & $\begin{array}{c}\text { Average } \\
\text { points } \\
\text { per } \mathrm{m}^{2}\end{array}$ & $\begin{array}{l}\text { No. of reference } \\
\text { measurements }\end{array}$ \\
\hline $\begin{array}{l}\text { 14 April 2015 } \\
\text { close to peak of winter }\end{array}$ & 85 & $285000 \mathrm{~m}^{2}$ & $157 \mathrm{~m}$ & 274 & $\begin{array}{l}22 \text { plots } \\
\text { (110 single points) }\end{array}$ \\
$\begin{array}{l}\text { HS accumulation } \\
\text { 21 September 2015 } \\
\text { completely snow-free }\end{array}$ & 274 & $363000 \mathrm{~m}^{2}$ & $133 \mathrm{~m}$ & 386 & - \\
\hline
\end{tabular}

$0.03 \mathrm{~m}$. The achieved average accuracy of the orientation process is $0.038 \mathrm{~m}$ ( $x=0.029 \mathrm{~m}, y=0.021 \mathrm{~m}, z=0.012 \mathrm{~m})$.

Simultaneously to the UAS data acquisition, HS reference measurements were acquired with a marked avalanche probe (Fig. 2). An investigation by Prokop et al. (2008) as well as our own experience show that such measurements are also affected by errors in the range of $0.05-0.10 \mathrm{~m}$. At every reference plot, five manual plumb vertical measurements within $1 \mathrm{~m}^{2}$ (at all corners and the center) were carried out and the center points were recorded with a Trimble GeoXH differential GNSS device, with an expected accuracy better than $0.10 \mathrm{~m}$.

\subsection{Brämabühl: exposed mountain top}

The test site Brämabühl is located at the top of the ski area Jakobshorn in Davos, Switzerland, at an elevation of $2500 \mathrm{~m}$ a.s.1. and is approximately $5.5 \mathrm{~km}$ linear distance from the test site Tschuggen (Fig. 1). At this test site, we expect a much higher variability of HS and in particular higher maximum HS values compared to the test site Tschuggen. The high wind exposure around the top of a crest at high elevation is expected to lead to a large amount of windblown snow. Additionally, the ski runs present within the area are typically areas for snow grooming and artificial snow production. The top of Brämabühl is mainly covered by high alpine meadow and small bushes (Fig. 10). No trees or larger bushes grow at this elevation and local climate. The mean slope angle of the test site is $30^{\circ}$, ranging from $0^{\circ}$ up to $90^{\circ}$ in the small rock faces. The reference measurement plots were acquired at slope angles between 5 and $41^{\circ}$ with a mean slope angle of $20^{\circ}$. The air temperature at the flight date, measured at an AWS located $5.5 \mathrm{~km}$ northwest of the test site at the same elevation, was $-2{ }^{\circ} \mathrm{C}$. The mean wind speed was $14 \mathrm{~km} \mathrm{~h}^{-1}$, the maximum wind speed $28 \mathrm{~km} \mathrm{~h}^{-1}$.

For this test site, near-infrared imagery was selected, which is expected to have higher contrast and lower reflection on snow-covered areas (Bühler et al., 2015b). Table 3 shows the data acquisition information and Fig. 3 the resulting orthophotos, with a spatial resolution of $0.025 \mathrm{~m}$. The same image overlap of $70 \%$ along-track and cross-track, like at the Tschuggen test site, was used. For the second field campaign, data acquisition was performed with the updated Falcon 8, explaining the much higher number of images and ground coverage in Table 3 . To cover the $500 \times 550 \mathrm{~m}$ Brämabühl test site we needed approximately $20 \mathrm{~min}$ and four batteries.

The image processing scheme from the Tschuggen experiment was repeated, but due to the smoother terrain with only a few clearly identifiable reference points, 10 artificial RPs (white plastic sheets with a symmetric black cross in the middle) were distributed and were measured with a Trimble GeoXH differential GNSS, with an expected accuracy of better than $0.10 \mathrm{~m}$. This approach allows a very accurate identification of the RPs in the imagery. However, the distribution of the artificial RPs is time-consuming and a meaningful distribution over the test site is often not possible due to e.g., avalanche danger. In addition the applied Trimble GeoXH has a lower positioning accuracy than the Leica TPS 1200 GNSS used at Tschuggen. Using 10 RPs, the achieved reference accuracies of $0.019 \mathrm{~m}$ in $x, 0.030 \mathrm{~m}$ in $y$ and $0.032 \mathrm{~m}$ in $z$ direction, results in a combined error of $0.048 \mathrm{~m}$.

The snow-covered imagery was referenced by taking natural RPs, which are clearly visible in the snow-free and snowcovered imagery (Fig. 3 ). The corresponding $x, y$ and $z$ coordinates of the snow-free imagery were used to reference the snow-covered imagery. This approach ensures an accurate co-registration of the two DSMs. However, it is only possible if snow-free areas contain enough features that are well visible and that are sufficiently distributed over the test site. The achieved georeferencing accuracy with 10 reference points is $0.155 \mathrm{~m}(x=0.079 \mathrm{~m}, y=0.102 \mathrm{~m}, z=0.086 \mathrm{~m})$; the result is worse than for the artificial RPs, as the natural RPs are harder to locate exactly.

Simultaneously to the winter UAS data acquisition, HS was measured with a marked avalanche probe at 22 plots as reference data, locating the center points of the plots using the Trimble Geo XH GNSS. 


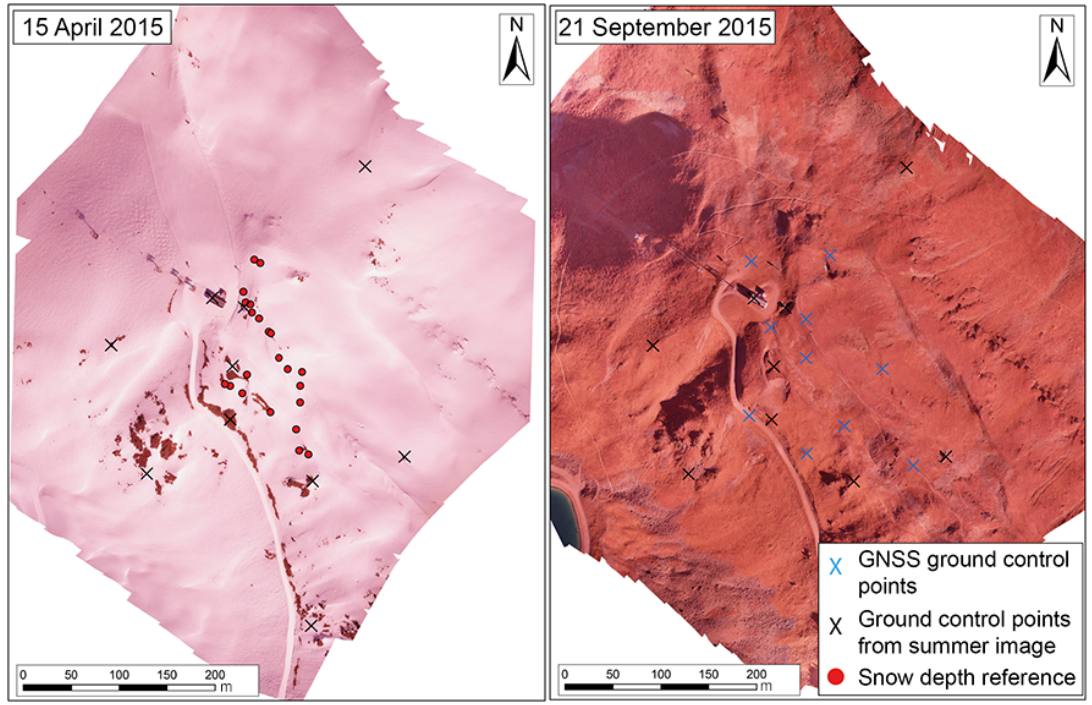

Figure 3. Near-infrared orthophotos snow-covered (left panel) and snow-free (right panel), acquired over the Brämabühl test site including the applied reference points and reference HS measurements.

\section{Results and validation}

\subsection{Tschuggen: valley bottom}

To produce the high spatial resolution $(0.10 \mathrm{~m})$ HS maps, the snow-free DSM (29 September 2015) has been subtracted from the snow-covered DSMs (11 March, 24 April and 12 May 2015). These maps reveal the high spatial variability of HS already present at sheltered locations in alpine terrain (Fig. 4, top panels). Particularly in the southeastern part of the test site, areas with complex topography exist. Patches with nearly no snow in wind-facing areas (luv) and pockets filled by windblown snow with HS up to $2 \mathrm{~m}$ in the wind-sheltered areas (lee) are located within less than $1 \mathrm{~m}$ distance. For the area depicted in Fig. 4, the mean HS $\bar{x}$ and the standard deviation $\sigma$ decrease from $\bar{x}=0.66 \mathrm{~m}$ and $\sigma=0.36$ on 11 March 2015 to $\bar{x}=0.31 \mathrm{~m}$ and $\sigma=0.31$ on 24 April 2015 and to $\bar{x}=0.01 \mathrm{~m}$ and $\sigma=0.09$ on 12 May. Because HS maps from different dates are available, including approximately the peak of winter HS accumulation (11 March 2015), the spatial distribution of HS change as the percentage of remaining snow compared to the maximum HS can be calculated and visualized. Prior to the generation of the relative HS change maps, the snow-covered areas were separated from snow-free patches using a simple unsupervised classification, based on the three spectral bands of the orthophoto. All snow-free areas have been set to zero HS. Isolated negative snow depth values, mainly caused by summer vegetation (Sect. 5.4), are not masked out but depicted as $0 \mathrm{HS}$ in the maps.

The locations of the probe measurements are depicted in Fig. 2. We compare the mean $\bar{x}$ and the standard deviation $\sigma$ of the five manual measurements per plot with the $\bar{x}$ and $\sigma$ of all pixels $(10 \times 10=100)$ within the $1 \mathrm{~m}^{2}$ box around the center localized with differential GNSS. The results of this comparison are depicted in Fig. 5.

The HS root mean square error (RMSE) over all 50 reference plots is $0.25 \mathrm{~m}$ and there is an average underestimation of HS by $0.2 \mathrm{~m}$. For a more detailed analysis we divide the reference measurements in two classes based on the manual analysis of the $0.025 \mathrm{~m}$ spatial resolution snow-free orthophoto acquired on 28 September 2015: (a) short grass/rocks, where no high vegetation is present and (b) bushes/high grass, where the surface of the dense vegetation is more than $0.10 \mathrm{~m}$ higher than the bare ground. In the second class, the snow-free DSM is higher than the terrain without vegetation. Because the snow presses the grass and bushes to the ground in winter, the difference between the snow-covered and snow-free DSM results in a systematic underestimation of HS. For the class of short grass/rocks, the RMSE is $0.07 \mathrm{~m}$ and there is a mean shift of only $0.05 \mathrm{~m}$ for all three flight dates. For the class of bushes/high grass, on the other hand, the RMSE is $0.30 \mathrm{~m}$ and there is a bias of $0.29 \mathrm{~m}$, corresponding to the mean height of bushes and tall grass within the investigation area. For snow hydrological applications, it is also important to gain information on the standard deviation $\sigma$ of HS within a specific plot. Even though the reference plots are only $1 \mathrm{~m}^{2}$ we find $\sigma$ values up to $0.2 \mathrm{~m}$. The RMSE of $\sigma$ is $0.04 \mathrm{~m}$, based on all reference measurements, and there is no clear difference between the two investigated classes at all three flight dates.

To assess the repeatability of the UAS HS mapping, we analyze the altitude deviation of the different DSM at 10550 grid cells on the snow-free road. The calculated RMSE values compared to the summer DSM (28 September) are $0.093 \mathrm{~m}$ (11 March), $0.052 \mathrm{~m}$ (24 April) and $0.045 \mathrm{~m}$ (12 


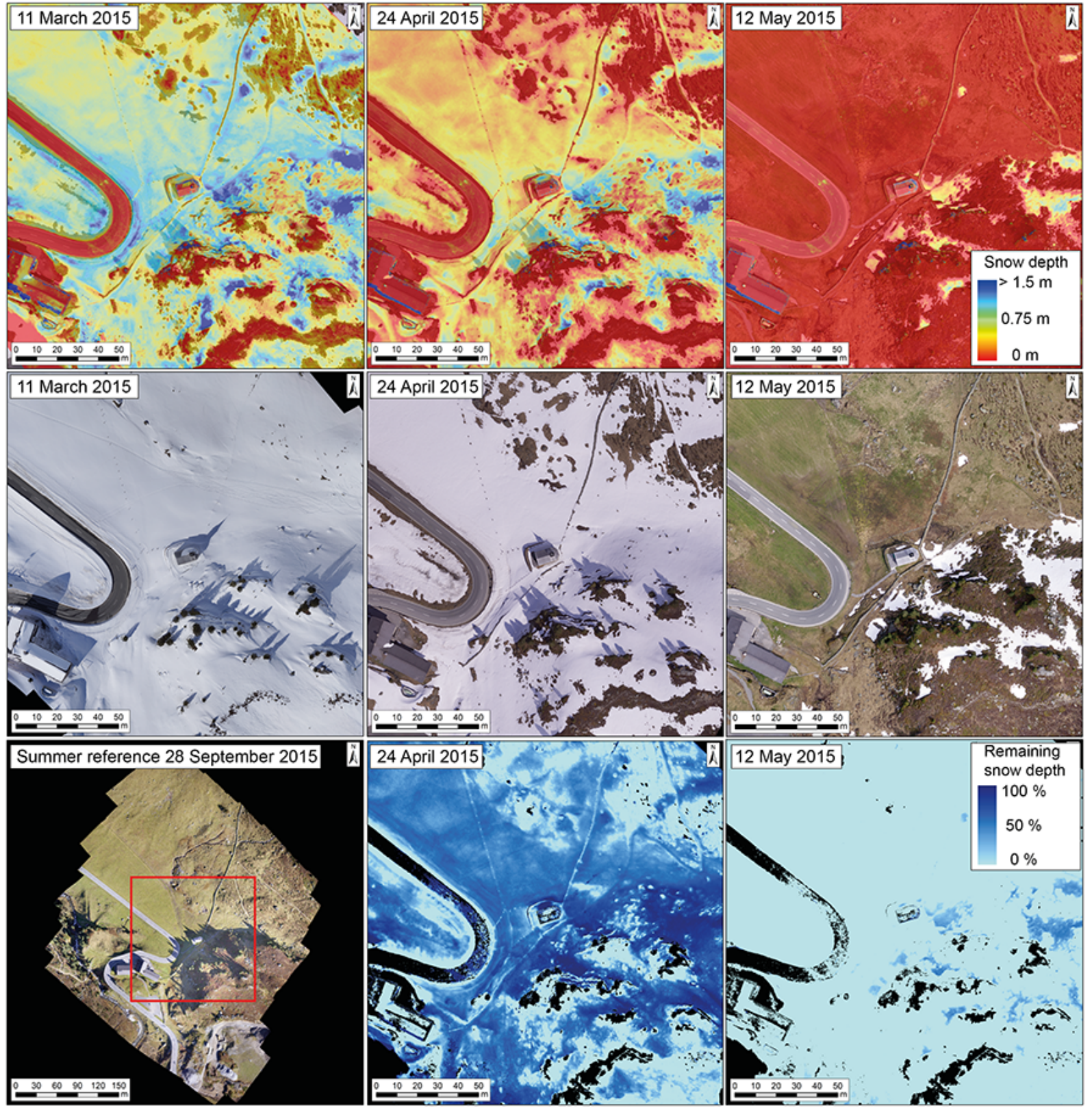

Figure 4. HS maps (top panels) and corresponding orthophotos (middle panels) of the area around the chapel in the center of the test site. At the bottom the orthophoto of the snow-free reference (bottom left panel) and the spatial distribution of melt rates as percentage of remaining snow compared to the peak of winter (11 March 2015) are depicted. Black areas depict a lack of data values.

May 2015). This indicates that the error of the method is smaller than $0.1 \mathrm{~m}$.

\subsection{Brämabühl: mountain top}

The HS map with a spatial resolution of $0.1 \mathrm{~m}$ shows different characteristics compared to the Tschuggen test site. The expected higher HS values of up to $5 \mathrm{~m}$ are clearly visible in Fig. 6. The close-up of the central part reveals interesting details such as the linear feature of buried hiking paths in the northwest or the snow grooming on the ski tracks. Over the entire area we calculate a mean HS $\bar{x}=1.41 \mathrm{~m}$ and $\sigma=0.78$. Both $\bar{x}$ and $\sigma$ are more than twice as high as at the Tschuggen test site. The high spatial variability becomes even more obvious in the 3-D view. We provide an animation of this 3-D visualization as a Supplement to the paper (mp4 3-D movie, Bühler et al., 2016). Snow-filled bowls lay directly next to ridges where nearly all snow has been blown off. HS differences reach up to $5 \mathrm{~m}$ within only a few meters' horizontal distance. Artificial terrain features such as hiking paths and 

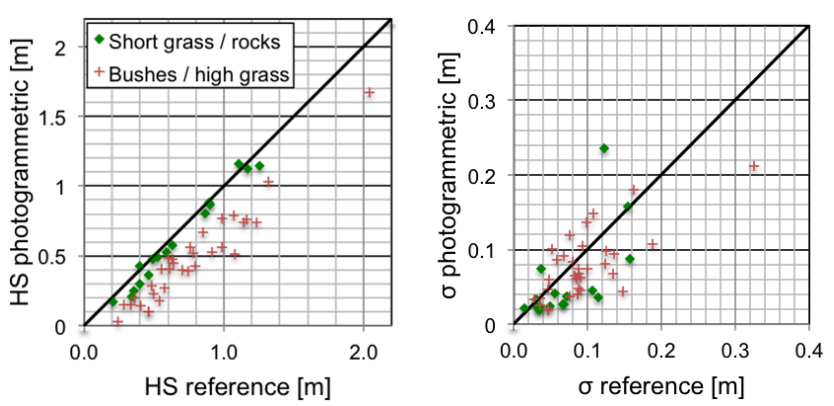

Figure 5. Statistical evaluation of the HS measurements (left panel) and the standard deviations $\sigma$ of HS within a specific reference plot (right panel). The overall correlation coefficient $R^{2}$ for the HS values is $0.84\left(R^{2}=0.98\right.$ for the class short grass/rocks and $R^{2}=0.92$ for the class bushes/high grass).

the edges of the ski track can easily be identified in the HS map. The gray features on the top and on the left side are the station building of the chair lift Brämajet and its masts. This visualization highlights the role of wind in combination with small terrain features for the spatial variability of HS.

The mean HS distribution classified by the terrain expositions confirms the visual impression that the south-facing slopes have much lower HS values than the north-facing slopes (Fig. 7). Additionally, the standard deviation of the mean HS shows a tendency to be smaller at southern expositions (SE, S and SW). This slope aspect analysis was performed on the snow-free DSM, which was resampled to $1 \mathrm{~m}$ to filter out small exposition changes. Such statistical evaluation enables a more detailed analysis of mountain HS distribution on local to regional scale.

The comparison of the photogrammetric HS with manual HS measurements results in a RMSE of $0.15 \mathrm{~m}$ and a very high correlation coefficient of $R^{2}=0.99$ (Fig. 8). The photogrammetric HS values are, on average, $0.11 \mathrm{~m}$ lower than the manual measurements. The summer vegetation can at least partly explain the difference, as dense grass and small bushes cover the peak of Brämabühl. The comparison of the standard deviations within a reference plot results in a bias of $0.03 \mathrm{~m}$; the RMSE is $0.06 \mathrm{~cm}$. These results confirm the high accuracy of the photogrammetric HS measurements we found at the Tschuggen test site.

\section{Discussion}

Based on the experience gained at the two presented test sites, the following key points require a more detailed discussion because they are crucial for the application of UASs in high alpine terrain.

\subsection{UASs applied in high alpine terrain}

Steep terrain, high altitudes, low temperatures and often wind speeds of more than $10 \mathrm{~m} \mathrm{~s}^{-1}$ are typical for high alpine re- gions. To successfully apply UASs, the platform and sensor must be able to handle such conditions and have to be easily transportable in a backpack on foot or on skis. The key limitation of the applied Falcon 8 UAS is the comparably short flight time of 6 to $10 \mathrm{~min}$ with one battery charge at elevations above $2000 \mathrm{~m}$ a.s.l. This also limits the range of the UAS. As a consequence, the pilot position has to be close to the area of interest, which is often difficult or even impossible, for example if snow avalanche release zones have to be mapped. A multicopter UAS can be started and landed by hand, which is a strong advantage in alpine terrain. Based on our experience, this stands in contrast to the application of fixed-wing UASs, which require large flat areas to safely land, but such areas are typically hard to find in high alpine terrain. Cold temperatures of down to $-30^{\circ} \mathrm{C}$ are a major problem for battery transportation. As soon as the battery is deployed and running in the UAS there is self-heating. Therefore it is critical that the batteries are transported in a heated environment for example close to the body, otherwise they will lose a large part of their performance before taking off, reducing the already short flight time. On the other hand, our experiences with the UAS regarding high winds were surprising. Even under foehn conditions with gusty winds of up to $20 \mathrm{~m} \mathrm{~s}^{-1}$, the acquired imagery was of high quality and the flight plan and its specific overlap could be accomplished. Our experience shows that fixed-wing UASs achieve longer flight times per battery charge (20-60 min), but are less stable in windy conditions, are less easy to transport and to fly and they need gentle terrain to land. In our opinion, this limits their successful application in alpine terrain considerably.

\subsection{Photogrammetry on snow-covered terrain}

For a long time, photogrammetry on snow-covered terrain was considered unfeasible, due to low contrast, a limitation only recently overcome as highlighted in current studies (Bühler et al., 2015a; Lee et al., 2008; Nolan et al., 2015). The smoother the snow surface, the harder it gets for the structure-from-motion software to identify meaningful matching points. This becomes obvious if we look at homogenous areas within the shaded DSM at shadowed and at well-illuminated snow-covered locations (Fig. 9). In shadowed areas (e.g., shadow of the chapel tower) the clearly visible noise introduced to the DSM shows amplitudes of up to $0.40 \mathrm{~m}$. In the bright, very homogenous areas, the noise shows amplitudes of up to $0.15 \mathrm{~m}$. This indicates that a fresh snow surface is less suitable than an older, weathered surface; but due to strong winds and large differences in radiation, alpine snow surfaces develop detectable features such as sastrugi or wind ripples already during or very shortly after snowfall. Very homogenous snow surfaces occur only within very small parts of our test sites.

Additional problems occur if reflections of the sun on the snow saturate the camera sensor. Therefore it is recommended that the camera exposure time is properly set and 


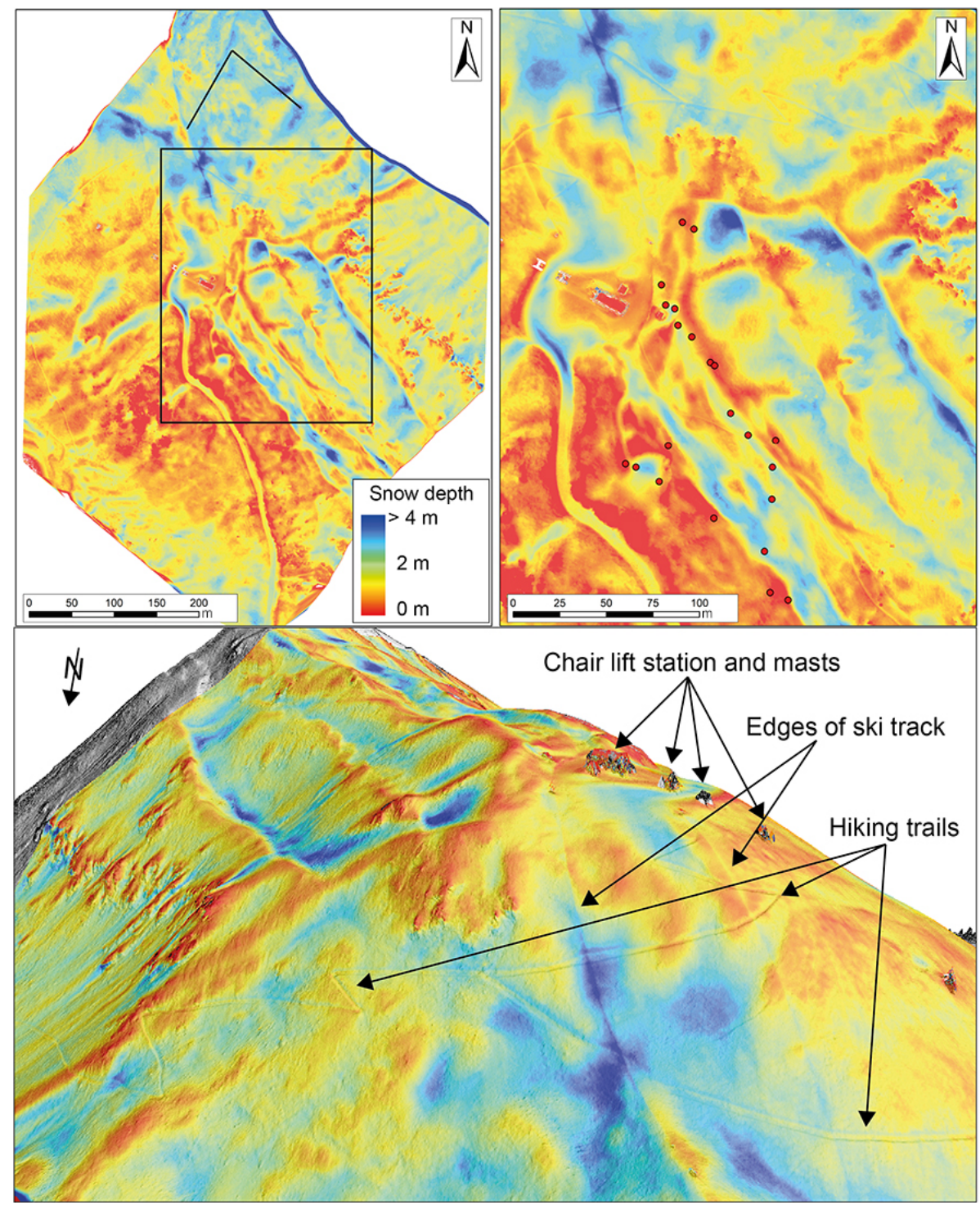

Figure 6. Overall HS map of the Brämabühl test site (top left panel) and close-up of the central part (top right panel). The locations of the reference plots are displayed as red circles. 3-D view of the HS draped over the hillshade of the snow-free DSM facing from north to south (bottom panel).

the imagery is stored in raw format using the full bit depth of the sensor, typically 10 to 14 bits. Standard JPEG image compression, which is the default storage setting for most cameras, is limited to 8 bits, storing only 256 grayscale values per band. However, further investigations are required to quantify the benefit of 12 bit image storage over the 8 bit JPEG compression on snow-covered areas.

As snow absorbs more energy in the near-infrared (NIR) part $(\lambda \approx 760-2500 \mathrm{~nm})$ of the electromagnetic spectrum than in the visible part $(\lambda \approx 400-700 \mathrm{~nm})$ and the reflection is sensitive to snow grain size (Warren, 1982) at the snow surface. Therefore, additional features are expected to be discriminated if NIR data can be used (Bühler et al., 2015b). However, further studies have to investigate the real benefit of NIR bands for photogrammetric HS mapping in more detail. This might only be significant if multi-imager cameras with narrow NIR bands and simultaneous band acquisition are applied.

\subsection{Orthorectification}

Exact relative georeferencing (co-registration) between the two DSMs is essential for correct HS calculation (snowcovered DSM minus snow-free DSM). Even small shifts in $x$ and $y$ can lead to large differences in $z$ direction on steep terrain. The following referencing approaches exist: 

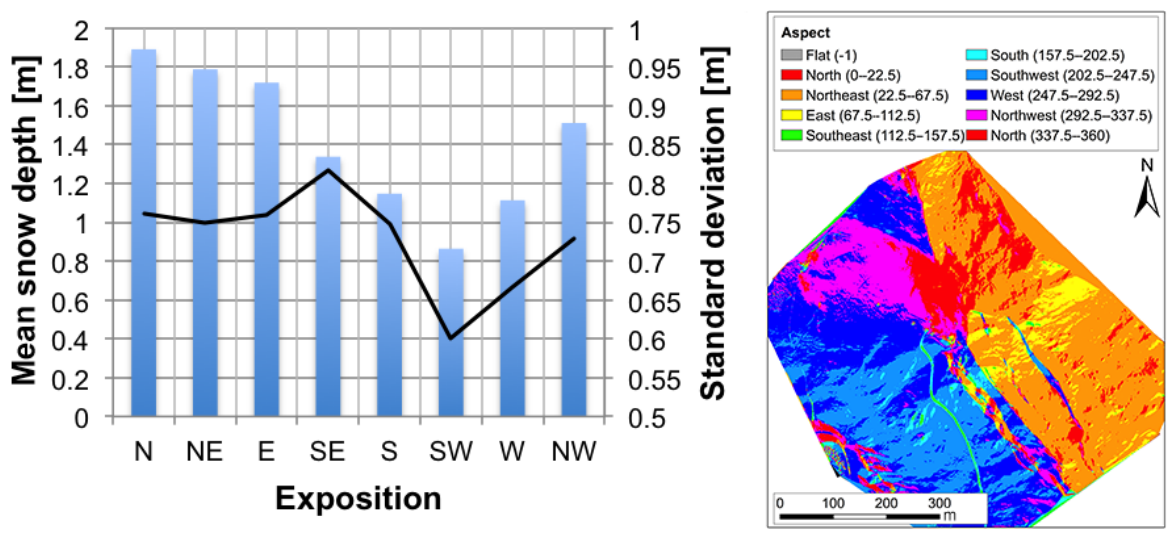

Figure 7. Statistical evaluation of the mean HS (bars) and its standard deviation (line), classified by the exposition (left panel) and exposition map (right panel).
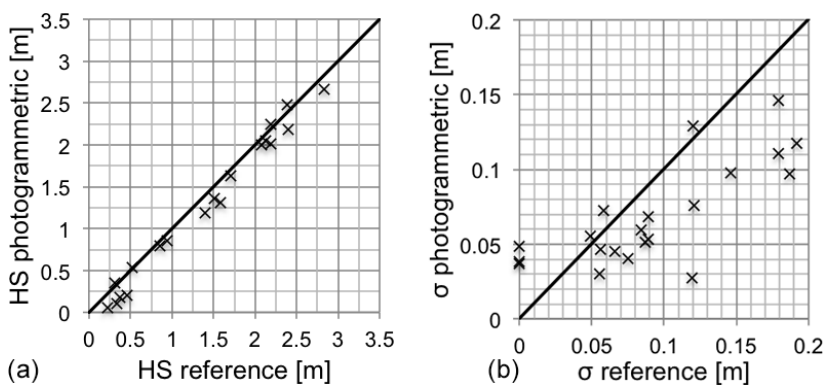

Figure 8. Statistical evaluation of the HS measurements (left panel) and the standard deviations $\sigma$ of HS within a reference plot (right panel).

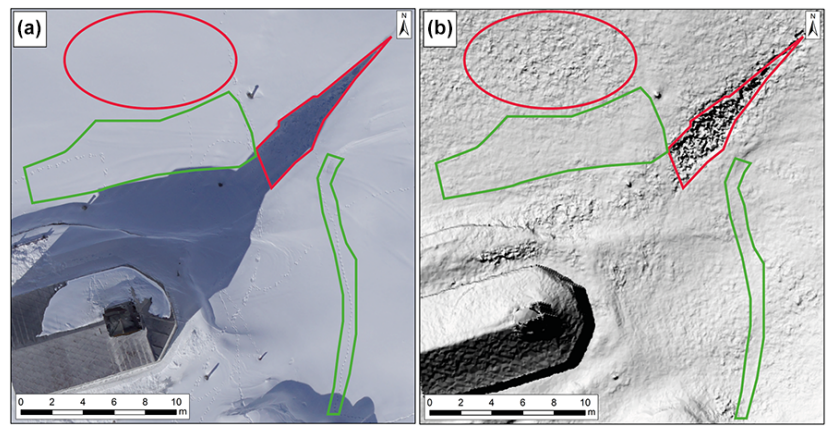

Figure 9. Winter orthophoto of the area close to the chapel within the test site Tschuggen (a) and hillshade of the derived DSM (b). Areas in red show very homogeneous snow surfaces either in cast shadow or nearly saturated areas. Areas marked in green are areas with better contrast at the snow surface due to tracks of animals or wind features.

a. absolute referencing with artificial RPs measured with differential GNSS;

b. relative referencing with natural RPs that are well visible in the snow-free and the snow-covered imagery; c. absolute referencing of one DSM with differential GNSS and then relative referencing of the second DSM by identifying points in the second DSM that are well visible.

A major drawback of method (a) is that all reference points have to be manually deployed and measured with differential GNSS devices to achieve accuracy in the range of centimeters to a decimeter. They should be distributed equally over the entire area of interest and all elevation bands. In high alpine terrain this is often not possible, for example due to avalanche danger. The methods (b) and (c) exclude the possibility of a potential GNSS shift but are only applicable if areas with distinct terrain features exist that are not covered by snow. This was the case at our test sites but might not be feasible in winters with exceptionally high amounts of snow. The referencing strategy has to be evaluated carefully prior to a UAS HS mapping campaign. A direct matching of the snow-covered to the snow-free point cloud (Gruen and Akca, 2005) is not feasible as the terrain shows large differences over most parts due to the snow cover.

RPs would not be necessary if a very accurate (better than $0.05 \mathrm{~m}$ ) GNSS/IMU system were available directly on the UAS. First, UAS products with such high-accuracy GNSS sensors are already available on the market. However, an initial investigation by Harder et al. (2016) indicates that the achieved orientation accuracy is not sufficient for snow depth mapping without ground reference measurements.

\subsection{Underlying vegetation}

Within the accuracy range of the HS maps of $0.05-0.15 \mathrm{~m}$, the vegetation at the base of the snow cover has a strong influence on the results. At the test site Tschuggen small bushes, mainly alpine rose, juniper and erica, rise up to $0.50 \mathrm{~m}$ above ground in summer (Fig. 10a). In winter they are pressed down to the ground by the snowpack but form a snow-free layer at the bottom of the snowpack which can have a depth 


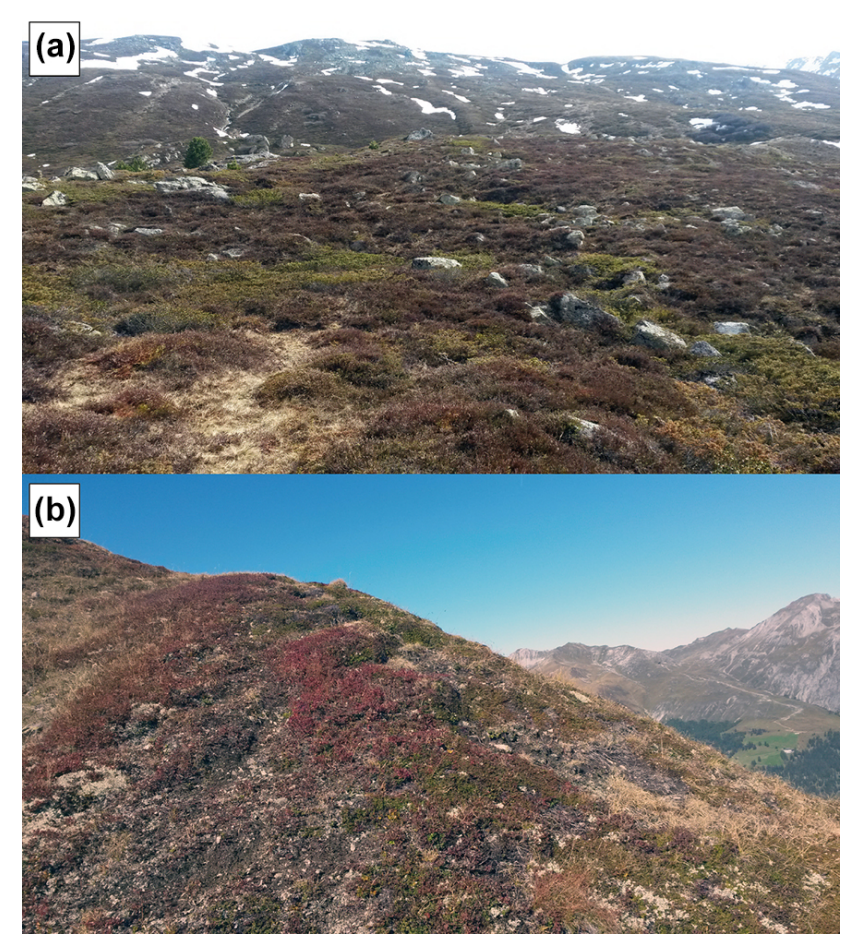

Figure 10. (a) Photograph of the bushes that rise up to $0.50 \mathrm{~m}$ above ground and patches of low grass at the test site Tschuggen. (b) Photograph of the shallow vegetation at the test site Brämabühl with maximum elevation of approximately $0.15 \mathrm{~m}$.

of a few centimeters to decimeters (Feistl et al., 2014). This leads to a systematic underestimation of HS mapped with photogrammetry (snow-free DSM is too high) as well as a systematic overestimation of HS measured manually with the avalanche probe because the probe penetrates the snowfree bottom layer and sometimes even the first layers of the ground. The "real" HS is most probably a value between the manual probe and the photogrammetric measurements. High grass, on the other hand, is usually pressed down to the ground completely, only leaving a snow-free layer of less than a few centimeters (Fig. 10b). This makes the probe measurements more reliable but can falsify the photogrammetric measurements if the grass is high during the snow-free data acquisition. Alpine meadows should therefore be surveyed right after mowing or late in autumn while the grass is low. From our experience, it is very difficult to correct the photogrammetric HS based on underlying vegetation because the elevation differences vary very much within short distances. A possibility might be to apply a vegetation classification based on the orthophotos to correct the underestimation of HS in areas with many bushes. But there is a high risk to introduce new errors and this possibility has to be investigated in more detail in the future. Photogrammetric HS mapping is difficult above, below and around trees, as trees are nearly always moved by wind and the resulting ambiguous tree top positions interfere with image matching. Additionally, areas below trees are not visible in the nadir imagery. Therefore laser scanning, measuring first and last returns or even full wave form signals, is still the best choice for investigations in forested areas (Moeser et al., 2015).

\section{Conclusions}

UAS-based digital photogrammetry is able to map the spatial variability of alpine HS with accuracies of 0.07 to $0.15 \mathrm{~m}$ RMSE compared to traditional manual measurements with avalanche probes. These accuracies are in the same range as HS measurements acquired by terrestrial laser scanning (Deems et al., 2013) and reported in the manned-airplanebased study by Nolan et al. (2015) and the UAS-based studies by Vander Jagt et al. (2015), de Michele et al. (2016) and Harder et al. (2016). It is clearly better than the RMSE of $0.30 \mathrm{~m}$ reported by Bühler et al. (2015a), using an ADS80 survey camera mounted on a manned airplane, but can only cover considerably smaller areas. Fixed-wing UASs, flying at high altitudes above ground, would be able to cover larger areas of several square kilometers. Future investigations have to clarify how accurate the results from such platforms can be as the spatial resolution of the input imagery is worse and the results might get much more affected by wind.

UASs enable fast, flexible, repeatable and detailed analysis of the spatial distribution of the mountain snow cover over several hectare areas. We successfully applied a complete photogrammetric workflow at a sheltered test site at the valley bottom (Tschuggen) and at an exposed test site at a mountain top (Brämabühl), mapping extreme HS variability of up to $5 \mathrm{~m}$ within less than $3 \mathrm{~m}$ distance, confirming the important role of wind and terrain features on HS distribution in alpine regions (Mott et al., 2010).

A key to robust photogrammetric HS measurements is the accurate co-registration of the snow-free and the snowcovered digital surface models (DSMs). Even small shifts in $x$ and/or $y$ direction can lead to large shifts in $z$, in particular within steep terrain. To avoid shifts introduced by GNSS measurements, we propose referencing the snowcovered DSM directly on the snow-free DSM; but this is only possible if snow-free areas exist that contain point or linear features that are well visible. Another important point is that alpine vegetation, such as bushes and tall grass, leads to an overestimation of snow-free DSM elevations, resulting in underestimated HS values. This can introduce errors in HS values of up to $0.50 \mathrm{~m}$.

We expect that UASs will get more and more important for environmental mapping and that they have the potential to change the frequency and quality of geodata acquisition fundamentally. 


\section{Data availability}

The underlying data sets (original UAS imagery and reference measurements) as well as the 3-D snow depth animation can be accessed by contacting the corresponding author Yves Bühler (buehler@slf.ch) directly.

\section{The Supplement related to this article is available online at doi:10.5194/tc-10-1075-2016-supplement.}

Acknowledgements. Parts of this work were supported by the Austrian Academy of Sciences (ÖAW) under the project RPAS4SNOW.

Edited by: E. Berthier

\section{References}

Basnet, K., Muste, M., Constantinescu, G., Ho, H., and Xu, H.: Close range photogrammetry for dynamically tracking drifted snow deposition, Cold Reg. Sci. Technol., 121, 141-153, doi:10.1016/j.coldregions.2015.08.013, 2015.

Bavay, M., Lehning, M., Jonas, T., and Löwe, H.: Simulations of future snow cover and discharge in Alpine headwater catchments, Hydrol. Process., 23, 95-108, 2009.

Bilodeau, F., Gauthier, G., and Berteaux, D.: The effect of snow cover on lemming population cycles in the Canadian High Arctic, Oecologia, 172, 1007-1016, 2013

Bühler, Y., Marty, M., Egli, L., Veitinger, J., Jonas, T., Thee, P., and Ginzler, C.: Snow depth mapping in high-alpine catchments using digital photogrammetry, The Cryosphere, 9, 229243, doi:10.5194/tc-9-229-2015, 2015a.

Bühler, Y., Meier, L., and Ginzler, C.: Potential of operational, high spatial resolution near infrared remote sensing instruments for snow surface type mapping, IEEE Geosci. Remote S., 12, 821825, 2015b.

Bühler, Y., Adams, M., Bösch, R., and Stoffel, A.: Animation of 3-D snow depth at Brämabühl, doi:10.13140/RG.2.1.2770.5204, 2016.

Cline, D. W.: Measuring alpine snow depths by digital photogrammetry: Part 1. conjugate point identification, Proceedings of the Eastern Snow Conference, 8-10 June 1993, Quebec City, Canada, 1993.

Cline, D. W.: Digital Photogrammetric Determination Of Alpine Snowpack Distribution For Hydrologic Modeling, Colorado State University, CO, USA, 1994.

Colomina, I. and Molina, P.: Unmanned aerial systems for photogrammetry and remote sensing: A review, ISPRS J. Photogramm., 92, 79-97, 2014.

Dall'Asta, E., Delaloye, R., Diotri, F., Forlani, G., Fornari, M., Morra di Cella, U., Pogliotti, P., Roncella, R., and Santise, M.: Use of Uas in a High Mountain Landscape: The Case of Gran Sommetta Rock Glacier (Ao), ISPRS Archives, XL-3/W3, 391397,2015
Danzi, M., Di Crescenzo, G., Ramondini, M., and Santo, A.: Use of unmanned aerial vehicles (UAVs) for photogrammetric surveys in rockfall instability studies, Rend. Online Soc. Geol. It., 24, 82-85, 2013.

Deems, J. S., Painter, T. H., and Finnegan, D. C.: Lidar measurement of snow depth: A review, J. Glaciol., 59, 467-479, 2013.

Deems, J. S., Gadomski, P. J., Vellone, D., Evanczyk, R., LeWinter, A. L., Birkeland, K. W., and Finnegan, D. C.: Mapping starting zone snow depth with a ground-based lidar to assist avalanche control and forecasting, Cold Reg. Sci. Technol., 120, 197-204, doi:10.1016/j.coldregions.2015.09.002, 2015.

de Michele, C., Avanzi, F., Passoni, D., Barzaghi, R., Pinto, L., Dosso, P., Ghezzi, A., Gianatti, R., and Della Vedova, G.: Using a fixed-wing UAS to map snow depth distribution: an evaluation at peak accumulation, The Cryosphere, 10, 511-522, doi:10.5194/tc-10-511-2016, 2016.

Eckerstorfer, M., Bühler, Y., Frauenfelder, R., and Malnes, E.: Remote sensing of snow avalanches: Recent advances, potential, and limitations, Cold Reg. Sci. Technol., 121, 126-140, 2016.

Egli, L., Jonas, T., Grünewald, T., Schirmer, M., and Burlando, P.: Dynamics of snow ablation in a small Alpine catchment observed by repeated terrestrial laser scans, Hydrol. Process., 26, 1574 1585, 2011.

Elder, K., Rosenthal, W., and Davis, R. E.: Estimating the spatial distribution of snow water equivalence in a montane watershed, Hydrol. Process., 12, 1793-1808, 1998.

Enßle, F., Fritz, A., and Koch, B.: Comparing Icesat/Glas Based Elevation Heights with Photogrammetric Terrain Heights from Uav-Imagery on the East Tibetan Plateau, ISPRS Archives, XL3/W3, 385-390, 2015.

Feistl, T., Bebi, P., Dreier, L., Hanewinkel, M., and Bartelt, P.: Quantification of basal friction for technical and silvicultural glide-snow avalanche mitigation measures, Nat. Hazards Earth Syst. Sci., 14, 2921-2931, doi:10.5194/nhess-14-2921-2014, 2014.

Fernández, T., Pérez, J. L., Cardenal, F. J., López, A., Gómez, J. M., Colomo, C., Delgado, J., and Sánchez, M.: Use of a light UAV and photogrammetric techniques to study the evolution of a landslide in Jaén (southern spain), ISPRS Archives, XL-3/W3, 241-248, 2015.

Fierz, C., Armstrong, R. L., Durand, Y., Etchevers, P., Greene, E., McClung, D. M., Nishimura, K., Satyawali, P. K., and Sokratov, S. A.: The International classification for seasonal snow on the ground, IACS, UNESCO, Paris, France, 2009.

Gruen, A. and Akca, D.: Least squares 3D surface and curve matching, ISPRS J. Photogramm., 59, 151-174, 2005.

Grünewald, T., Schirmer, M., Mott, R., and Lehning, M.: Spatial and temporal variability of snow depth and ablation rates in a small mountain catchment, The Cryosphere, 4, 215-225, doi:10.5194/tc-4-215-2010, 2010.

Harder, P., Schirmer, M., Pomeroy, J., and Helgason, W.: ACCURACY OF SNOW DEPTH ESTIMATION IN MOUNTAIN AND PRAIRIE ENVIRONMENTS BY AN UNMANNED AERIAL VEHICLE, The Cryosphere Discuss., doi:10.5194/tc2016-9, in review, 2016.

Jonas, T., Marty, C., and Magnusson, J.: Estimating the snow water equivalent from snow depth measurements in the Swiss Alps, J. Hydrol., 378, 161-167, 2009. 
Koenderink, J. J. and van Doorn, A. J.: Affine structure from motion, J. Opt. Soc. Am. A 8, 377-385, 1991.

Lee, C. Y., Jones, S. D., Bellman, C. J., and Buxton, L.: DEM creation of a snow covered surface using digital aerial photography, The International Archives of the Photogrammetry, Remote Sensing and Spatial Information Sciences, Part B8, Beijing, China, 831-835, 2008.

McClung, D. M. and Schaerer, P.: The Avalanche Handbook, The Mountaineers Books, Seattle, USA, 2006.

Melvold, K. and Skaugen, T.: Multiscale spatial variability of lidarderived and modeled snow depth on Hardangervidda, Norway, Ann. Glaciol., 54, 273-281, 2013.

Moeser, D., Morsdorf, F., and Jonas, T.: Novel forest structure metrics from airborne LiDAR data for improved snow interception estimation, Agr. Forest Meteorol., 208, 40-49, 2015.

Mott, R., Schirmer, M., Bavay, M., Grünewald, T., and Lehning, M.: Understanding snow-transport processes shaping the mountain snow-cover, The Cryosphere, 4, 545-559, doi:10.5194/tc-4-5452010, 2010.

Mysterud, A., Stenseth, N. C., Yoccoz, N. G., Langvatn, R., and Steinheim, G.: Nonlinear effects of large-scale climatic variability on wild and domestic herbivores, Nature, 410, 1096-1099, 2001.

Nolan, M., Larsen, C., and Sturm, M.: Mapping snow depth from manned aircraft on landscape scales at centimeter resolution using structure-from-motion photogrammetry, The Cryosphere, 9, 1445-1463, doi:10.5194/tc-9-1445-2015, 2015.

Prokop, A.: Assessing the applicability of terrestrial laser scanning for spatial snow depth measurements, Cold Reg. Sci. Technol., 54, 155-163, 2008.

Prokop, A., Schirmer, M., Rub, M., Lehning, M., and Stocker, M.: A comparison of measurement methods: Terrestrial laser scanning, tachymetry and snow probing for the determination of the spatial snow-depth distribution on slopes, Ann. Glaciol., 49, 210-216, 2008.

Prokop, A., Schön, P., Singer, F., Pulfer, G., Naaim, M., Thibert, E., and Soruco, A.: Merging terrestrial laser scanning technology with photogrammetric and total station data for the determination of avalanche modeling parameters, Cold Reg. Sci. Technol., 110, 223-230, 2015.

Ryan, J. C., Hubbard, A. L., Box, J. E., Todd, J., Christoffersen, P., Carr, J. R., Holt, T. O., and Snooke, N.: UAV photogrammetry and structure from motion to assess calving dynamics at Store Glacier, a large outlet draining the Greenland ice sheet, The Cryosphere, 9, 1-11, doi:10.5194/tc-9-1-2015, 2015.
Schaffhauser, A., Adams, M., Fromm, R., Jörg, P., Luzi, G., Noferini, L., and Sailer, R.: Remote sensing based retrieval of snow cover properties, Cold Reg. Sci. Technol., 54, 164-175, 2008.

Schweizer, J., Kronholm, K., Jamieson, J. B., and Birkeland, K. W.: Review of spatial variability of snowpack properties and its importance for avalanche formation, Cold Reg. Sci. Technol., 51, 253-272, 2008.

Smith, F., Cooper, C., and Chapman, E.: Measuring Snow Depths by Aerial Photography, Proceedings of the Western Snow Conference, April 1967, Boise, Idaho, USA, 1967.

Tampubolon, W. and Reinhardt, W.: Uav Data Processing for Rapid Mapping Activities, ISPRS Archives, XL-3/W3, 371-377, 2015.

Thibert, E., Bellot, H., Ravanat, X., Ousset, F., Pulfer, G., Naaim, M., Hagenmuller, P., Naaim-Bouvet, F., Faug, T., Nishimura, K., Ito, Y., Baroudi, D., Prokop, A., Schön, P., Soruco, A., Vincent, C., Limam, A., and Héno, R.: The full-scale avalanche test-site at Lautaret Pass (French Alps), Cold Reg. Sci. Technol., 115, 30 41,2015

Tucker, C. J.: Red and photographic infrared linear combinations for monitoring vegetation, Remote Sens. Environ., 8, 127-150, 1979.

Vander Jagt, B., Lucieer, A., Wallace, L., Turner, D., and Durand, M.: Snow Depth Retrieval with UAS Using Photogrammetric Techniques, Geosciences, 5, 264-285, 2015.

Verhoeven, G.: Taking computer vision aloft - archaeological threedimensional reconstructions from aerial photographs with photoscan, Archaeol. Prospect., 18, 67-73, 2011.

Warren, S.: Optical Properties of Snow, Rev. Geophys. Space GE, 20, 67-89, 1982.

Whitehead, K., Moorman, B. J., and Hugenholtz, C. H.: Brief Communication: Low-cost, on-demand aerial photogrammetry for glaciological measurement, The Cryosphere, 7, 1879-1884, doi:10.5194/tc-7-1879-2013, 2013.

Wipf, S., Stoeckli, V., and Bebi, P.: Winter climate change in alpine tundra: Plant responses to changes in snow depth and snowmelt timing, Climatic Change, 94, 105-121, 2009. 